\title{
Pengaruh Perlakuan Ratun, Jenis Hanjeli dan Kadar Air terhadap Pertumbuhan Tanaman Hanjeli Jenis Pulut (Coix lacryma-jobi var. ma- yuen) dan Batu (Coix lacryma-jobi var. stenocarpa)
}

\author{
A. Miftah Fauzi ${ }^{1^{*}}$, Dedi Widayat ${ }^{2}$, dan Tati Nurmala ${ }^{2}$ \\ ${ }^{1}$ Mahasiswa Program Pascasarjana Agronomi, Fakultas Pertanian, Universitas Padjadjaran \\ ${ }^{2}$ Fakultas Pertanian, Universitas Padjadjaran \\ *Alamat korespondensi: miftah18003@mail.unpad.ac.id
}

\begin{abstract}
Effect of ratoon's treatment, type of hanjeli and soil water content on growth and yield of Coix lacryma-jobi var. ma-yuen and Coix lacryma-jobi var. stenocarpa
\end{abstract}

Information about the effect of soil water content on growth and yield of Job's tears varieties (Coix lacryma-jobi var. ma-yuen and Coix lacryma-jobi var. stenocarpa) plants is very important in increasing yields of Job's tears cultivation. This study aimed to examine the effect of different soil water levels on the growth and yield of C. lacryma-jobi var. ma-yuen and C. lacryma-jobi var. stenocarpa grown from seed and ratoon. Both types of Job's tears were planted in the Ciparanje experimental garden, Faculty of Agriculture, Universitas Padjadjaran, Jatinangor District, Sumedang Regency, West Java. The experiment was carried out from July 2018 to August 2019. The results demonstrated that the Job's tears growing through seed gave better growth and yield performances compared to plant growth from ratoon. Ratooning on the field with $60 \%$ soil moisture showed better harvest index and seed weight compared to ratoon grown on lower soil moisture of $40 \%$. The Job's tears varieties differences were only affected the number of clumps in which suggested genetic regulated.

Keywords: Hanjeli, Soil Water Content, Ratoon, Batu, Pulut

\begin{abstract}
ABSTRAK
Informasi mengenai pengaruh kadar air tanah terhadap pertumbuhan dan hasil tanaman hanjeli Pulut (Coix lacryma-jobi var. ma-yuen) dan Batu (Coix lacryma-jobi var. stenocarpa) sangat penting dalam peningkatan hasil panen dari budidaya tanaman hanjeli. Penelitian ini bertujuan untuk mengkaji seberapa besar pengaruh kadar air tanah yang berbeda terhadap pertumbuhan dan hasil hanjeli jenis Pulut dan Batu yang ditanam dari biji dan ratun. Tanaman hanjeli jenis Batu dan Pulut ditanam di Kebun Percobaan Ciparanje Fakultas Pertanian Universitas Padjadjaran, Kecamatan Jatinangor, Kabupaten Sumedang, Jawa Barat dengan kondisi lahan yang mempunyak kadar air berbeda (40\% dan 60\%). Percobaan dilaksanakan dari bulan Juli 2018 sampai Agustus 2019. Hasil penelitian menunjukkan bahwa jenis penanaman dan kadar air memengaruhi berbagai karakter pertumbuhan dan karakter hasil tanaman hanjeli baik jenis pulut maupun batu. Penanaman tanaman utama melalui biji dan kadar air 60\% pada lahan percobaan menunjukkan hasil yang lebih baik berdasarkan karakter pertumbuhan dan hasil yang diamati dibandingkan dengan ratuning. Penanaman ratun pada kondisi lahan dengan kadar air 60\% memberikan hasil indeks panen dan bobot biji per rumpun yang lebih baik dibandingkan jika ditanam pada kondisi lahan dengan kadar air 40\%. Jenis tanaman hanjeli pulut dan batu hanya menghasilkan perbedaan jumlah anakan saja yang disinyalir karena kandungan genetiknya.
\end{abstract}

Kata kunci: Hanjeli, Kadar Air Tanah, Ratun, Batu, Pulut 


\section{PENDAHULUAN}

Isu penting untuk mengatasi kerawanan pangan dan mengurangi impor terigu adalah mengembangkan sumber bahan pangan alternatif berbasis tepung, baik untuk memenuhi kebutuhan rumah tangga maupun industri pangan lainnya. Salah satu serealia yang potensial dan memiliki prospek yang baik untuk dikembangkan oleh masyarakat adalah tanaman hanjeli (jali-jali) (Nurmala \& Irwan, 2007).

Hanjeli (Coix lacryma-jobı) merupakan tanaman sumber karbohidrat dan juga pangan fungsional yang dikenal di Indonesia dengan beberapa nama lain seperti hajeli, jelai, jali, japen, atau jeten. Sementara di negara lain hanjeli disebut Job's tears (Australia), adlay (Filipina), Sila (Fiji) dan mayuen (China). Tanaman hanjeli berasal dari Asia Tenggara dan diduga berasal dari Indonesia. Di Indonesia tanaman hanjeli sudah mulai dikembangkan pada beberapa daerah khususnya di daerah Jawa Barat yakni, Ciamis, Tanjung Sari, Bandung, Cirebon, Sukabumi dan Garut. Tanaman hanjeli juga berpotensi untuk dikembangkan sebagai tanaman adaptif terhadap perubahan iklim karena tahan terhadap kekeringan atau tergenang air (Ruminta \& Nurmala, 2016). Potensi hasil hanjeli berkisar antara 4-6 ton/ha biji berkulit atau sekitar 3-4 ton/ha beras hanjeli, bila ditanam dengan jarak tanam $100 \times 50 \mathrm{~cm}$. Budidaya hanjeli di daerah Kiarapayung, Jatinangor dilaporkan dapat menghasilkan 400-600 kg biji berkulit dari 100 tumbak lahan (Nurmala dkk., 2009).

Cekaman kekeringan dapat menghambat produksi bobot kering hasil tanaman, terutama karena efek penghambatannya terhadap perluasan dan pengembangan daun. Hal tersebut kemudian dapat menyebabkan menurunnya penangkapan cahaya (Anjum et al., 2011). Cekaman kekeringan yang menyebabkan kadar air rendah meningkatkan respon penutupan stomata pada tanaman, sehingga menurunkan pengambilan $\mathrm{CO}_{2}$ dari udara dan membuat proses fotosintesis menurun. Kemarau yang panjang memunculkan cekaman kekeringan serta menghambat segala kegiatan pertanian. Kekeringan mengakibatkan perubahan aktivitas fisiologis penting yang diawali dengan penutupan stomata untuk menekan transpirasi, penurunan input karbondioksida, penurunan jumlah klorofil, dan pada akhirnya penurunan laju fotosintesis netto. Akar merespon kekeringan dengan mensintesis dan mengirimkan sinyal asam absisat (ABA) yang mengakibatkan penutupan stomata sehingga menurunkan transpirasi dan serapan $\mathrm{CO}_{2}$. Kekeringan juga menyebabkan penurunan kandungan klorofil a, b, dan nisbah klorofil a/b (Mastur, 2016).

Tanaman hanjeli sebetulnya membutuhkan lebih sedikit air daripada tanaman padi sawah (Setiasih dkk., 2017). Tanaman hanjeli ada yang sudah dibudidayakan dan sebagian masih liar. Di Kabupaten Bandung, tanaman hanjeli ditemukan terdiri atas tipe pulut (Coix lacryma-jobi var. mayuen) dan batu (Coix lacryma-jobi var. stenocarpa). Tipe pulut termasuk tanaman hanjeli yang banyak dibudidayakan oleh masyarakat Kabupaten Bandung, terutama di daerah Cicalengka, Tanjungjaya, Rancaekek, Cipongkor, dan Punclut. Tanaman hanjeli yang dibudidayakan kebanyakan merupakan tipe pulut, karena mudah dibuat menjadi tepung beras, sedangkan tipe batu biasanya digunakan untuk ornamen (Qosim \& Nurmala, 2011).

Jenis hanjeli tipe batu merupakan tanaman liar dan keras. Umumnya digunakan untuk manikmanik pada kalung, sedangkan hanjeli yang dibudidayakan lunak dan dapat dibuat bubur. Di Indonesia, tanaman hanjeli menyebar di berbagai ekosistem lahan pertanian yang bermacam-macam di daerah iklim kering ataupun iklim basah, lahan kering dan lahan basah contohnya ditemukan di Sumatra, Sulawesi, Kalimantan. Di Jawa Barat, tanaman tersebut diusahakan oleh petani masih secara konvensional sebagai tanaman langka, secara sporadis ditemukan di Kabupaten Bandung di Punclut, Cipongkor, Gunung Halu, Kiarapayung, Tanjungsari Kabupaten Sumedang, Sukabumi, Garut, Ciamis dan Indramayu (Nurmala, 2010).

Tanaman hanjeli termasuk serealia yang akarnya mampu membentuk anakan baru. Kemampuan ini memang biasa dimanfaatkan petani untuk menanam secara ratun yang biasa disebut sebagai tanam berulang, meskipun hasil yang didapat tidak sebagus tanaman awal karena hasil bisa berkurang sampai 50\% (Nugraha, 2019). Penerapan budidaya padi dengan sistem ratun dilaporkan dapat memberikan tambahan produksi $40-60 \%$ per musim tanam, dengan menghemat input, biaya, tenaga dan waktu (Susilawati dkk., 2010). Pengujian penanaman tanaman padi gogo yang ditanam dengan memanfaatkan kelembapan tanah dilaporkan oleh Arsa dkk. (2020). Pada pengujian tersebut Penelitian tersebut melaporkan bahwa pada tingkat kelembapan tanah 60\% KL (Kapasitas Lapang) tidak 
memengaruhi jumlah malai, sementara pada tingkat kelembapan $40 \% \mathrm{KL}$ terdeteksi jumlai malai mulai berkurang. Tujuan dari penelitian ini adalah untuk mengetahui pengaruh cara tanam hanjeli (ratun dan biji) dan jenis hanjeli yang ditanam pada tingkat kadar air tanah berbeda terhadap pertumbuhan dan hasil tanaman hanjeli.

\section{BAHAN DAN METODE}

Percobaan tanaman utama dilaksanakan bulan Juli 2018 sampai dengan Januari 2019, sedangkan tanaman ratun dilaksanakan bulan Mei sampai dengan Agustus 2019 di Kebun Pecobaan Ciparanje Fakultas Pertanian Universitas Padjadjaran, Jatinangor, Sumedang. Lokasi penelitian lahan kering memiliki ketinggian $\pm 780 \mathrm{~m}$ dpl, memiliki ordo tanah Inceptisol dengan tipe curah hujan C3 menurut Oldeman. Tanaman hanjeli jenis batu dan pulut yang digunakan merupakan koleksi Laboratorium Tanaman Pangan Universitas Padjadjaran. Perlakuan penanaman tanaman utama melakukan dengan penyeleksian benih, sementara penanaman ratun dilakukan dengan memangkas batang tanaman hanjeli utama sesudah panen dengan tinggi $20 \mathrm{~cm}$. Rancangan percobaan yang digunakan adalah split plot. Uji normalitas menggunakan uji Kormogorov-Smirnov dengan bantuan SPSS Versi 16. Uji perbedaan pengaruh perlakuan menggunakan uji Duncan pada taraf $5 \%$. Tanaman berasal dari tanaman utama dan biji digunakan sebagai petak utama (main plot) dan jenis hanjeli pada kadar air tanah berbeda sebagai anak petak (sub plot). Untuk penanaman tanaman utama, lahan (seluas 9,6 $\mathrm{m}^{2}$ dengan ukuran 2,4 $\mathrm{m} \mathrm{x} 4 \mathrm{~m}$ ) diolah satu minggu sebelum penanaman.

Pupuk kandang ayam sebagai pupuk dasar yang diberikan pada saat satu minggu sebelum tanam dengan dosis 2 ton/hektar. Penanaman dilakukan dengan jarak tanam $60 \times 80 \mathrm{~cm}$ dengan kedalaman lubang tanam $5 \mathrm{~cm}$. Pemupukan susulan dilakukan sebanyak dua kali dengan menggunakan NPK dengan perbandingan 16-16-16. Pemupukan susulan pertama dilakukan pada 7 hari setelah tanam dengan dosis $200 \mathrm{~kg} / \mathrm{ha}$ atau $10 \mathrm{~g} /$ tanaman, sedangkan pemupukan susulan kedua dilakukan pada saat 11 minggu setelah tanam dengan dosis 100 $\mathrm{kg} / \mathrm{ha}$ atau $5 \mathrm{~g} /$ tanaman. Setelah tanaman utama panen, dilanjutkan dengan penanaman ratun. Ratun diperoleh dengan memotong tanaman utama setinggi $20 \mathrm{~cm}$. Pemeliharaan ratun sama dengan tanaman utama. Pemeliharaan tanaman hanjeli ratun meliputi penyiraman, penyiangan, pemupukan, pengendalian hama dan penyakit tanaman. Penyiangan gulma dilakukan setiap ada gulma yang tumbuh sepanjang penelitian.

Pemupukan bertujuan untuk memenuhi unsur hara yang dibutuhkan oleh tanaman (Qosim dkk., 2013). Pupuk Nitrogren, Posfor dan Kalium (NPK) $250 \mathrm{~kg} / \mathrm{ha}$ yang diberikan $2 \mathrm{x}$ dengan $1 / 3$ dosis pupuk NPK majemuk (15:15:15) dan 2/3 dosis pupuk yang sama. Pemupukan pertama dilakukan pada 7 hari setelah ratun, sedangkan pemupukan kedua dilakuakan pada saat 10 minggu setelah ratun. Penanaman tanaman utama dan ratun pada lahan dengan kadar air yang berbeda dilakukan dengan penyiraman dengan menggunakan sprinkler pada setiap petak. Penyiraman dilakukan secara berkala setiap hari (kadar air 60\%) dan setiap empat hari sekali (kadar air 40\%). Penyiraman dikendalikan dengan menggunakan soil water content meter merk Gardsens hingga mencapai kadar air yang dikehendaki.

Pengendalian serangan hama pada tanaman utama dan ratun dilakukan dengan cara pemberian pestisida berbahan aktif profenofos. Pengendalian gulma dilakukan dengan cara penyiangan pada saat tanaman berumur 1, 5, dan 10 Minggu Setelah Tanam (MST) dan Minggu Setelah Ratun (MSR) atau sesuai dengan kondisi di lapangan. Karakter tanaman yang diamati meliputi tinggi tanaman jumlah anakan, jumlah srisip (tunas samping), nisbah pupus akar (NPA), jumlah biji per rumpun, rendeman biji pecah kulit, indeks panen, indeks stabilitas hasil, umur tanaman, bobot biji per tanaman, dan indeks toleran cekaman. Tinggi tanaman diukur dengan penggaris pada 18 MST dan 18 MSR. Analisis ragam sidik ragam split plot yang dianalisis dengan menggunakan Uji $\mathrm{F}$ pada taraf nyata $(\alpha) 5 \%$.

\section{HASIL DAN PEMBAHASAN}

Hasil analisis sidik ragam terhadap jenis penanaman, jenis hanjeli dan kadar air terhadap jumlah srisip, jumlah malai, nisbah pupus akar, jumlah biji dan bobot 100 biji tidak menunjukkan adanya interaksi. Oleh karena itu pada masingmasing parameter pertumbuhan tanaman hanjeli tadi hanya dapat dilihat pengaruh mandirinya saja dari setiap perlakuan (Tabel 1). Jenis penanaman tanaman hanjeli dan ratun menunjukkan adanya perbedaan yang signifikan terhadap jumlah srisip, jumlah malai, nisabah pupus akar, jumlah biji dan 
bobot 100 biji hanjeli. Terlihat bahwa pada tanaman utama yang ditanam dari biji memperoleh hasil yang lebih tinggi pada komponen parameter tersebut di atas dibandingkan bila menanam melalui ratun. Sementara penanaman hanjeli pada kadar air yang berbeda tidak menunjukkan adanya pengaruh pada nisbah pupus akar, jumlah biji dan bobot 100 biji. Pengaruhnya hanya terlihat pada karakter jumlah srisip dan jumlah malai, dimana hanjeli yang ditanam pada lahan dengan kadar air 60\% menghasilkan jumlah srisip dan jumlah malai yang lebih banyak dibandingkan dengan yang ditanam pada lahan dengan kadar air $40 \%$.
Sementara itu, hasil analisis sidik ragam terhadap komponen pertumbuhan yang lainnya yaitu tinggi tanaman maksimum, jumlah anakan maksimum, jumlah biji per rumpun, indeks panen, dan bobot biji per rumpun memperlihatkan adanya pengaruh dari interaksi antara jenis penanaman, jenis hanjeli dan kadar air pada lahan percobaan. Hasil uji lanjut dari parameter tersebut masingmasing disajikan pada Tabel 2 (tinggi tanaman maksimum), Tabel 3 (jumlah anakan maksimum), Tabel 4 (jumlah biji per rumpun), Tabel 5 (indeks panen), dan Tabel 6 (bobot biji per rumpun).

Tabel 1. Pengaruh jenis penanaman, jenis hanjeli dan penanaman pada lahan dengan kadar air yang berbeda terhadap berbagai karakter pertumbuhan tanaman hanjeli.

\begin{tabular}{lccccc}
\hline \multicolumn{1}{c}{ Perlakuan } & Jumlah Srisip & $\begin{array}{c}\text { Jumlah } \\
\text { Malai }\end{array}$ & $\begin{array}{c}\text { Nisbah Pupus } \\
\text { Akar (NPA) }\end{array}$ & Jumlah Biji & $\begin{array}{c}\text { Bobot 100 Biji } \\
(\mathrm{g})\end{array}$ \\
\hline \multirow{5}{*}{$\begin{array}{c}\text { Petak Utama } \\
\text { Ratun }\end{array}$} & $30,67 \mathrm{a}$ & $13,33 \mathrm{a}$ & $3,87 \mathrm{a}$ & $2,70 \mathrm{a}$ & $13,42 \mathrm{a}$ \\
Tanaman Utama & $71,58 \mathrm{~b}$ & $26,82 \mathrm{~b}$ & $6,89 \mathrm{~b}$ & $4,08 \mathrm{~b}$ & $24,50 \mathrm{~b}$ \\
\hline \multicolumn{5}{c}{ Anak Petak } \\
Jenis Batu pada 40\% & $45,83 \mathrm{a}$ & $20,43 \mathrm{ab}$ & $4,60 \mathrm{a}$ & $3,25 \mathrm{a}$ & $17,33 \mathrm{a}$ \\
Jenis Batu pada 60\% & $54,83 \mathrm{~b}$ & $22,37 \mathrm{~b}$ & $5,98 \mathrm{a}$ & $3,90 \mathrm{a}$ & $20,17 \mathrm{a}$ \\
Jenis Pulut pada 40\% & $46,67 \mathrm{a}$ & $16,40 \mathrm{a}$ & $4,84 \mathrm{a}$ & $3,07 \mathrm{a}$ & $20,00 \mathrm{a}$ \\
Jenis Pulut pada 60\% & $57,17 \mathrm{~b}$ & $19,00 \mathrm{ab}$ & $6,09 \mathrm{a}$ & $3,35 \mathrm{a}$ & $18,33 \mathrm{a}$ \\
\hline \multicolumn{5}{l}{ Keterangan: Angka yang dikuti dengan huruf yang sama pada kolom yang sama tidak berbeda nyata berdasarkan uji Duncan taraf 5\%. }
\end{tabular}

Secara umum, jenis penanaman hanjeli memengaruhi tinggi tanaman maksimum, jumlah anakan maksimum, jumlah biji per rumpun, indeks panen, dan bobot biji per rumpun. Dapat dilihat tanaman hanjeli yang ditanam berasal dari biji memiliki ketinggian tanaman yang lebih tinggi, jumlah anakan yang lebih banyak, jumlah biji yang lebih banyak, indeks panen lebih tinggi dan bobot biji per rumpun yang lebih banyak dibandingkan dengan tanaman hanjeli ratun. Demikian pula halnya dengan perlakuan kadar air, tanaman hanjeli yang ditanam pada lahan dengan kadar air yang lebih tinggi menunjukan keragaan tanaman yang lebih baik. Sementara jenis hanjeli dalam hal ini pulut dan batu tidak menunjukkan adanya pengaruh yang cukup berarti, kecuali pada komponen jumlah anakan yang disinyalir disebabkan perbedaan genetik dari kedua jenis tanaman tersebut.

Menurut Kurniasari dkk. (2010) cekaman air menghambat pertumbuhan tinggi tanaman karena terganggunya aktivitas meristem apikal akibat terbatasnya kandungan air dalam jaringan. Hal tersebut merupakan faktor penting dalam pertumbuhan dan perkembangan sel. Energi yang seharusnya dipergunakan untuk pertumbuhan terpakai untuk mengatasi kekeringan sehingga pertumbuhan terhambat.

Jumlah anakan pada tanaman hajeli ratun lebih rendah dibandingkan dengan tanaman utama. Hal ini sejalan dengan penelitian Susilawati dkk. (2010) pada tanaman padi. Susilawati dkk. (2010) melaporkan bahwa jumlah anakan tanaman utama produktif berkisar antara 12,2-39,3 anakan sementara jumlah anakan produktif tanaman ratun sebanyak 5,7-30 anakan. Secara visual tunas-tunas ratun mulai keluar pada hari ke-2 hingga hari ke-7, dengan jumlah anakan yang muncul paling banyak terjadi pada hari kelima. Perbedaan waktu keluar tunas dan laju pertumbuhan ratun tampaknya sangat tergantung pada kondisi tunggul tanaman utama. Hal ini disebabkan karena beberapa karakter penting yang secara langsung berkaitan dengan kemampuan tanaman padi dalam menghasilkan ratun adalah morfologi tanaman utama yang mempunyai batang besar, kokoh dan hijau, rumpun dan daun yang lebat, serta keadaan tunggul yang tetap vigor dan hijau setelah panen tanaman utama. 
Tabel 2. Pengaruh jenis penanaman, jenis hanjeli dan penanaman pada lahan dengan kadar air yang berbeda terhadap karakter tinggi tanaman maksimum.

\begin{tabular}{ccccc}
\hline Ratun & \multicolumn{2}{c}{ Jenis Batu } & \multicolumn{2}{c}{ Jenis Pulut } \\
\cline { 2 - 5 } & $40 \%(\mathrm{j} 1)$ & $60 \%(\mathrm{j} 2)$ & $40 \%(\mathrm{j} 3)$ & $60 \%(\mathrm{j} 4)$ \\
\hline Ratun & $120,00 \mathrm{a}$ & $126,66 \mathrm{a}$ & $109,33 \mathrm{a}$ & $120,00 \mathrm{a}$ \\
$(\mathrm{r} 1)$ & $\mathrm{A}$ & $\mathrm{A}$ & $\mathrm{A}$ & $\mathrm{A}$ \\
Tanaman Utama & $224,00 \mathrm{~b}$ & $277,33 \mathrm{~b}$ & $204,00 \mathrm{~b}$ & $229,00 \mathrm{~b}$ \\
(r2) & $\mathrm{B}$ & $\mathrm{C}$ & $\mathrm{A}$ & $\mathrm{B}$ \\
\hline
\end{tabular}

Keterangan: Angka yang diikuti dengan huruf yang sama (huruf besar arah horizontal dan huruf kecil arah vertikal) tidak berbeda nyata berdasarkan uji Duncan taraf $5 \%$.

Tabel 3. Pengaruh jenis penanaman, jenis hanjeli dan penanaman pada lahan dengan kadar air yang berbeda terhadap karakter jumlah anakan maksimum.

\begin{tabular}{ccccc}
\hline Ratun & \multicolumn{2}{c}{ Jenis Batu } & \multicolumn{2}{c}{ Jenis Pulut } \\
\cline { 2 - 5 } & $40 \%(\mathrm{j} 1)$ & $60 \%(\mathrm{j} 2)$ & $40 \%(\mathrm{j} 3)$ & $60 \%(\mathrm{j} 4)$ \\
\hline Ratun & $6,00 \mathrm{a}$ & $7,67 \mathrm{a}$ & $6,33 \mathrm{a}$ & $8,67 \mathrm{a}$ \\
(r1) & $\mathrm{A}$ & $\mathrm{A}$ & $\mathrm{B}$ & $\mathrm{B}$ \\
Tanaman Utama & $15,66 \mathrm{~b}$ & $22,33 \mathrm{~b}$ & $16,33 \mathrm{~b}$ & $22,33 \mathrm{~b}$ \\
(r2) & $\mathrm{A}$ & $\mathrm{B}$ & $\mathrm{A}$ & $\mathrm{B}$ \\
\hline Keterangan: & Angka yang diikuti dengan huruf yang sama (huruf besar arah horizontal dan huruf kecil arah vertikal) tidak berbeda \\
& nyata berdasarkan uji Duncan taraf 5\%.
\end{tabular}

Tabel 4. Pengaruh jenis penanaman, jenis hanjeli dan penanaman pada lahan dengan kadar air yang berbeda terhadap karakter jumlah biji per rumpun.

\begin{tabular}{ccccc}
\hline Ratun & \multicolumn{2}{c}{ Jenis Batu } & \multicolumn{2}{c}{ Jenis Pulut } \\
\cline { 2 - 5 } & $40 \%(\mathrm{j} 1)$ & $60 \%(\mathrm{j} 2)$ & $40 \%(\mathrm{j} 3)$ & $60 \%(\mathrm{j} 4)$ \\
\hline Ratun & $486,66 \mathrm{a}$ & $576,00 \mathrm{a}$ & $495,00 \mathrm{a}$ & $622,00 \mathrm{a}$ \\
$(\mathrm{r} 1)$ & $\mathrm{A}$ & $\mathrm{A}$ & $\mathrm{A}$ & $\mathrm{A}$ \\
Tanaman Utama & $1.196,6 \mathrm{~b}$ & $1.506,33 \mathrm{~b}$ & $1.045,67 \mathrm{~b}$ & $1.452,00 \mathrm{~b}$ \\
(r2) & $\mathrm{B}$ & $\mathrm{C}$ & $\mathrm{A}$ & $\mathrm{C}$ \\
\hline $\begin{array}{c}\text { Keterangan: } \\
\text { Angka yang diikuti dengan huruf yang sama (huruf besar arah horizontal dan huruf kecil arah vertikal) tidak berbeda } \\
\text { nyata berdasarkan uji Duncan taraf 5\%. }\end{array}$
\end{tabular}

Tabel 5. Pengaruh jenis penanaman, jenis hanjeli dan penanaman pada lahan dengan kadar air yang berbeda terhadap karakter indeks panen.

\begin{tabular}{ccccc}
\hline Ratun & \multicolumn{2}{c}{ Jenis Batu } & \multicolumn{2}{c}{ Jenis Pulut } \\
\cline { 2 - 5 } & $40 \%(\mathrm{j} 1)$ & $60 \%(\mathrm{j} 2)$ & $40 \%(\mathrm{j} 3)$ & $60 \%(\mathrm{j} 4)$ \\
\hline Ratun & $0,20 \mathrm{a}$ & $0,23 \mathrm{a}$ & $0,20 \mathrm{a}$ & $0,24 \mathrm{a}$ \\
(r1) & $\mathrm{A}$ & $\mathrm{B}$ & $\mathrm{A}$ & $\mathrm{B}$ \\
Tanaman Utama & $0,33 \mathrm{~b}$ & $0,45 \mathrm{~b}$ & $0,26 \mathrm{~b}$ & $0,33 \mathrm{~b}$ \\
(r2) & $\mathrm{B}$ & $\mathrm{C}$ & $\mathrm{A}$ & $\mathrm{B}$ \\
\hline
\end{tabular}

Keterangan: Angka yang diikuti dengan huruf yang sama (huruf besar arah horizontal dan huruf kecil arah vertikal) tidak berbeda nyata berdasarkan uji Duncan taraf 5\%.

Tanaman yang tumbuh dari ratun memiliki perakaran yang dangkal sehingga menyebabkan daerah serapan baik air maupun nutrisi menjadi terbatas (Hunsigi, 1989). Kondisi yang demikian diperparah ketika tanaman berada dalam cekaman kekeringan. Ratuning merupakan praktek budidaya konvensioanal yang membiarkan tanaman tumbuh kembali setelah proses panen selesai. Praktek budidaya ratuning mulai digencarkan kembali untuk mengurangi input budidaya tanaman (Torres et al., 2019). Terdapat beberapa kelemahan dari praktek budidaya tersebut antara lain selain jangkauan 
serapannya yang terbatas, kedalaman akar biasanya juga dangkal sehingga tanaman mudah roboh dan transisi antara akar lama dan tumbuhnya akar baru rentan merupakan masa rentan terhadap perubahan lingkungan (Hunsigi, 1989). Hal demikian yang menyebabkan tanaman hanjeli yang ditanam dari ratun menunjukkan keragaan yang kurang dibandingkan dengan tanaman utama. Akan tetapi, masa tumbuh tanaman ratun yang lebih pendek menjadikan teknik ini dapat terus dipraktekan.

Tabel 6. Pengaruh jenis penanaman, jenis hanjeli dan penanaman pada lahan dengan kadar air yang berbeda terhadap karakter bobot biji (g) per rumpun.

\begin{tabular}{ccccc}
\hline Ratun & \multicolumn{2}{c}{ Jenis Batu } & \multicolumn{2}{c}{ Jenis Pulut pada } \\
\cline { 2 - 5 } & $40 \%(\mathrm{j} 1)$ & $60 \%(\mathrm{j} 2)$ & $40 \%(\mathrm{j} 3)$ & $60 \%(\mathrm{j} 4)$ \\
\hline Ratun & $114,56 \mathrm{a}$ & $139,6 \mathrm{a}$ & $113,99 \mathrm{a}$ & $147,40 \mathrm{a}$ \\
(r1) & $\mathrm{A}$ & $\mathrm{B}$ & $\mathrm{A}$ & $\mathrm{B}$ \\
Tanaman Utama & $203,18 \mathrm{~b}$ & $305,95 \mathrm{~b}$ & $198,33 \mathrm{~b}$ & $280,00 \mathrm{~b}$ \\
(r2) & $\mathrm{A}$ & $\mathrm{B}$ & $\mathrm{A}$ & $\mathrm{B}$ \\
\hline Keterangan: & Angka yang diikuti dengan huruf yang sama (huruf besar arah horizontal dan huruf kecil arah vertikal) tidak berbeda \\
& nyata berdasarkan uji Duncan taraf 5\%.
\end{tabular}

\section{SIMPULAN}

Jenis penanaman dan kadar air memengaruhi berbagai karakter pertumbuhan dan karakter hasil tanaman hanjeli baik pulut maupun batu. Penanaman tanaman utama melalui biji dan kadar air $60 \%$ pada lahan percobaan menunjukkan hasil yang lebih baik berdasarkan karakter pertumbuhan dan hasil yang diamati. Jenis tanaman hanjeli yang digunakan hanya menunjukkan perbedaan jumlah anakan saja yang kemungkinan disebabkan oleh perbedaan genetik.

\section{UCAPAN TERIMA KASIH}

Penelitian selesai karena ada bantuan, kesempatan ini penulis mengucapkan terimakasih kepada Bapak Fiky Yulianto Wicaksono, SP., MP. dan Ibu Prof. Dr. Ir. Hj. Tati Nurmala yang telah memberikan kontribusi berupa fasilitas yaitu alat dan bahan penelitian.

\section{DAFTAR PUSTAKA}

Anjum, S-A, X Xie, L Wang, M-F Saleem, C Man, and W Lei. 2011. Morphological, physiological and biochemical responses of plants to drought stress. Agricultural Research. 6: 2026-2032.

Arsa, I-G-B-A, H-J-D Lalel, dan R Pollo. 2020. Respon komponen pertumbuhan dan hasil, serta kualitas aroma tiga varietas lokal padi gogo aromatik asal sumba barat daya terhadap tingkat kelembaban tanah. Crop Agro. 13: 2138.

Hunsigi, G. 1989. Ratooning in sugarcane. Outlook on Agriculture. 18 (4): 175-184.

Kurniasari, A-M., Adisyahputra, dan R Rosman. 2010. Pengaruh kekeringan pada tanah bergaram $\mathrm{NaCl}$ terhadap pertumbuhan tanaman nilam. Bul. Littro. 21:18-27.

Mastur. 2016. Respon Fisiologis Tanaman Tebu Terhadap Kekeringan. Buletin Tanaman Tembakau, Serat \& Minyak Industri. 8:98111.

Nugraha, E. 2019. Kisah Petani Hanjeli. Tersedia online pada https://www.scribd.com/doc/237129945/Kisa h-Petani-Hanjeli.

Nurmala, T. 2010. Potensi dan Prospek Pengembangan Hanjeli (Coix lacryma jobi L) sebagai Pangan Bergizi Kaya Lemak untuk Mendukung Diversifikasi Pangan Menuju Ketahanan Pangan Mandiri. Pangan, 20:41-48

Nurmala, T, dan A-W Irwan. 2007. Pangan Alternatif Berbasis Serelia Minor. Giratuna. Bandung.

Nurmala, T, W-A Qosim, dan T-S Achyar. 2009. Eksplorasi, Identifikasi dan Analisis Keragaman Plasma Nuftah Tanaman Hanjeli (Coix lacryma-jobi L.) Sebagai Sumber Bahan Pangan Berlemak di Jawa Barat. Laporan Penelitian Strategis Unpad. Jatinangor.

Qosim, W-A, dan T Nurmala. 2011. Eksplorasi, identifikasi dan analisis keragaman plasma nutfah tanaman hanjeli (Coix lacryma jobi L.) 
sebagai sumber bahan pangan berlemak di Jawa Barat. Pangan. 20:365-376.

Qosim, W-A, T Nurmala, A-W Irwan, dan M-C Damanik. 2013. Pengaruh pupuk NPK dan pupuk hayati BPF terhadap karakter pertumbuhan dan hasil empat genotip hanjeli (Coix lacryma jobi L.). Pangan. 22:357-364.

Ruminta, dan T Nurmala. 2016. Dampak perubahan pola curah hujan terhadap tanaman pangan lahan tadah hujan di Jawa Barat. Agrin. 20(2): 155-168.

Setiasih, I-S., M-B. Santoso, I Hanidah, dan H Marta. 2017. Pengembangan kapasitas masyarakat dalam menggunakan hanjeli sebagai alternatif pengganti beras sebagai pangan pokok dan produk olahan. Penelitian dan PKM. 4:129389.

Susilawati, B-S Purwoko, H Aswidinnoor, dan E Santosa. 2010. Keragaan varietas dan galur padi tipe baru Indonesia dalam sistem ratun. Agron. Indonesia. 38:177-184.

Torres, RO, MA Natividad, MR Quintana, and A Henry. 2019. Ratooning as management strategy for lodged or drought damaged rice crops. Crop Sciences. 60: 367-380. 